\title{
ANAESTHESIA FOR INTESTINAL SHORT CIRCUITING IN THE MORBIDLY OBESE WITH REFERENCE TO THE PATHOPHYSIOLOGY OF GROSS OBESITY
}

\author{
Gordon S. Fox
}

MANY REPORTS on anaesthesia for grossly obese subjects have been published.1-5 These reports emphasize the difficulties encountered in the management of obese subjects for anaesthesia and surgery.

We have recently had experience with the anaesthetic and post-operative management of 16 subjects who presented for intestinal bypass operations for gross obesity. We shall review the pathophysiology of this disease with particular reference to the cardiovascular and respiratory systems and shall present a technique of management which takes cognizance of these problems. The "Pickwickian syndrome" ${ }^{\text {" }}$ characterized by alveolar hypoventilation, right heart failure and polycythaemia will not be discussed due to its rarity and because we did not encounter a case in this series.

Intestinal short circuiting procedures are used to reduce weight in grossly obese patients after other methods have failed. Post-operative pulmonary complications are frequent and show a definite increase as the weight of the patients increases above ideal weight. ${ }^{7}$ The mortality rate after upper abdominal operations in obese patients is two and one half times that of the non-obese patient. ${ }^{8}$

Obesity is associated with pathological changes in the cardiovascular system. Hypertension is a common occurrence in obese patients ${ }^{9}$ and will diminish with weight reduction. ${ }^{10}$ Backman $^{11}$ measured intravascular pressures in nineteen patients weighing 108 to $172 \mathrm{~kg}$. Brachial artery pressures were raised above normal. At rest, mean pulmonary artery pressure and pulmonary capillary venous pressure were also above normal. During exercise, right ventricular pressure, mean pulmonary artery pressure and pulmonary capillary venous pressure increased abnormally as cardiac output increased. Cardiac output increases with increasing weight and may double the predicted cardiac output at ideal weight. ${ }^{12}$ Total blood volume is expanded but blood volume on a weight basis is less than normal and is low in relation to total body weight. ${ }^{11}$ Blood flow to adipose tissue forms an important fraction of the increased cardiac output because fat is an active metabolic tissue. ${ }^{11}$ The increased cardiac work load, elevated systemic and pulmonary pressure, and the enlarged stroke volume lead to muscular hypertrophy of the right and left ventricles. ${ }^{13}$ The increased cardiac work-load affects mainly the left ventricle. ${ }^{14}$

The anaesthetist, aware of these alterations, must avoid further stress to the cardiovascular system. Infusion of water and electrolytes requires careful regulation as 10 per cent of these patients may be in congestive heart failure. ${ }^{9}$ Similarly the

'Department of Anaesthesia, Royal Victoria Hospital \& McGill University, Montreal. 


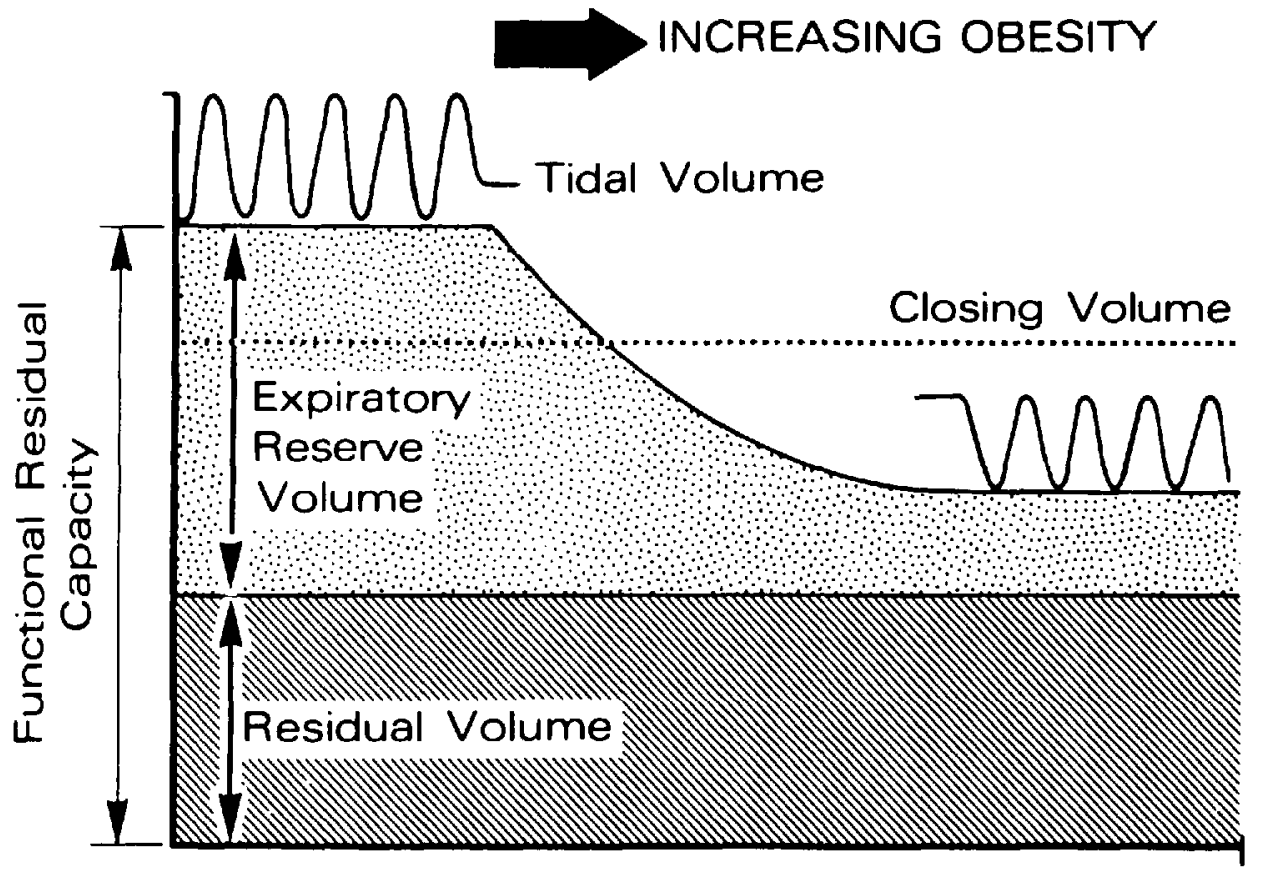

Ficune 1. The expiratory reserve volume is markedly decreased by gross obesity and consequently functional residual capacity falls below closing volume.

abnormal blood volume should be recognized before deciding on blood replacement. The systemic hypertension is sensitive to a high sympathetic tone secondary to hypoxaemia, hypercarbia, ineffective anaesthesia or inappropriate vasopresser therapy. Induction of anaesthesia in hypertensive patients frequently induces cardiac arrhythmias ${ }^{15}$ while concurrent antihypertensive medication may cause labile pressor responses. ${ }^{16}$ Spinal anaesthesia in the obese is associated with a 36 per cent incidence of significant hypotension. ${ }^{3}$

Prolonged post-operative immobilization can lead to phlebothrombosis. ${ }^{8}$ Two of the 16 patients in our series developed proven pulmonary emboli secondary to peripheral phlebothrombosis. One died from this complication.

Respiratory function is altered by gross obesity. The striking abnormality is the constant reduction of functional residual capacity (F.R.C.). ${ }^{17}$ The diminution of F.R.C. is caused by a decrease in the expiratory reserve volume (E.R.V.) (Figure 1). The measured functional residual capacities and expiratory reserve volumes of the patients in this series were consistently less than predicted values (Table I). Morbidly obese patients have F.R.C. values below closing volume in the seated and/or supine position and, therefore, dependent lung zones may be effectively closed throughout respiration ${ }^{18}$ so that inspired gas is distributed mainly to upper or non-dependent lung zones. A decrease in E.R.V. to $400 \mathrm{ml}$ or 21 per cent of predicted E.R.V. is usually associated with a fall in F.R.C. significantly large enough to shift gas distribution to non-dependent lung zones. ${ }^{17}$ The resulting mismatch of ventilation to perfusion results in a decreased $\dot{\mathrm{V}} \mathrm{a} / \mathrm{Q} \mathrm{c}$ ratio and consequently lowered arterial oxygen tensions. 
FOX: ANAESTHESIA IN THE MORBIDLY OBESE

TABLE I

Lung Volumes-Thirteen Patients

\begin{tabular}{lcc}
\hline & $\begin{array}{c}\text { Measured } \\
\text { Mean (S.D.) }\end{array}$ & $\begin{array}{c}\text { Predicted } \\
\text { Mean (S.D.) }\end{array}$ \\
\hline F.R.C. (L) & $1.72(0.22)$ & $2.99(0.38)$ \\
E.R.V. (L) & $0.36(0.26)$ & $1.37(0.24)$ \\
R.V. (L) & $1.29(0.17)$ & $1.69(0.19)$ \\
\hline F.R.C. = Functional residual capacity. & \\
E.R.V. = Expiratory reserve volume. & \\
R.V. = Residual volume. & \\
(S.D.) = \pm Standard deviation. &
\end{tabular}

Less obese patients may have a normal $\dot{V a} / \dot{Q} c$ while seated but are likely to lose this advantage when placed supine for abdominal operations because the E.R.V. is further diminished in this position. ${ }^{19}$

In addition, chest wall compliance may be markedly decreased in seated obese subjects and result in low total respiratory compliance ${ }^{20}$ Lung compliance remains normal. Decreased chest wall compliance is due to increased elastic resistance of the extrapulmonary structures to distension. Chest wall compliance declines further on changing from the seated to the supine position. Functionally the decreased chest wall compliance increases the oxygen cost of the work of breathing. ${ }^{20,21}$ Clinically, low total respiratory compliance and the high oxygen cost of the work of breathing may both contribute to the need for mechanical ventilation with a volume ventilator during anaesthesia.

Functional residual capacity decreases soon after the induction of anaesthesia if the patient is breathing spontaneously. ${ }^{22}$ Obesity and anaesthesia both reduce the F.R.C. ${ }^{22}$ and are associated with airway closure, gas trapping ${ }^{23}$ and in obese subjects a shift of ventilation to non-dependent lung zones. ${ }^{24}$ These changes reduce arterial oxygen tension. Controlled ventilation during anaesthesia with large tidal volumes may reverse this process by moving tidal ventilation above the closing volume and consequently increase arterial oxygen tension. ${ }^{25}$ Higher than usual inspired oxygen mixtures during anaesthesia will also help to bring arterial oxygen tensions to normal.

Noble $^{4}$ and Warner ${ }^{26}$ have emphasized difficulties with muscle relaxants in obese patients. Abnormally large amounts of these agents may be used in response to low chest wall compliance ${ }^{20}$ or to surgical difficulties. Reversal of these agents is often inadequate ${ }^{4}$ and attempts at spontaneous ventilation are frequently characterized by thoraco-abdominal incoordination, hypoxaemia and increasing hypercarbia which demand post-operative mechanical ventilation.

Spinal ${ }^{3}$ and epidural ${ }^{26}$ local anaesthetic dose requirements have been reported to be reduced in obese patients. Increased intra-abdominal pressure ${ }^{27}$ may shift blood from the inferior vena cava to the epidural venous system as in the pregnant female. ${ }^{28}$ This would effectively decrease the volume of the epidural space and cause a wider spread of injected local anaesthetic agents.

The technical difficulties encountered during anaesthesia and the post-operative period are listed in Table III. Blood pressure estimations using regular sized cuffs give falsely high measurements. ${ }^{29}$ 
TABLE II

\begin{tabular}{lcc}
\hline & & \\
& Body Weight (lb) & $\begin{array}{c}\text { Initial Dose } \\
\text { Lidocaine (mg) }\end{array}$ \\
\hline Mean & 303 & 294 \\
S.D. & \pm 61 & \pm 54 \\
Range & $275-425$ & $200-400$ \\
\hline
\end{tabular}

TABLE III

Obesity: Technical Difficulties

1. Sphygmomanometer reading - false high. Use wide cuff or direct arterial pressure.

2. Venipuncture and arterial puncture difficult.

3. Short fat neck - endotracheal intubation may be difficult.

4. Difficult to position for surgery and post-operative physiotherapy.

5, Airway may be difficult to maintain with a mask.

6. Nerve blocks, conduction anaesthesia; landmarks difficult to palpate.

Edelist ${ }^{1}$ clearly stated the objectives of an anaesthetic technique for abdominal surgery in the obese. They include strict maintenance of the airway, adequate muscle relaxation, optimum oxygenation, avoidance of the residual effects of muscle relaxants, provision of periodic sighs and adequate intra-operative and post-operative tidal volume and efficient post-operative analgesia.

We have established a technique of anaesthesia which fulfils these objectives and combines epidural and general anaesthesia but excludes the use of long-acting muscle relaxants, post-operative intubation and mechanical ventilation.

\section{Method of Anaesthesia and Post-Operative Management}

Mean patient body weights and weight ranges are shown in Table II.

Prior to operation the patient receives careful instruction regarding deepbreathing exercises for the post-operative period. During the anaesthetist's preoperative visit the anaesthetic technique is carefully explained and special emphasis is placed on examination of the patient's peripheral veins, radial pulses, vertebral column, and the configuration of the face and neck.

Vital capacity is measured after an arterial blood sample has been obtained for blood gas analysis. Both these measurements are made while the patient is lying at $45^{\circ}$ head up, since this is the position in which post-operative measurements are done. These serve as control measurements for comparison during the post-operative period.

After arrival in the operating room a secure intravenous infusion is established and the patient is prepared for epidural anaesthesia. The epidural space is located using the loss of resistance technique at the most convenient site closest to the interspace between the first and second lumbar vertebrae. We use a slightly longer and heavier \#16 Tuohy needle than usual in these patients. Frequently the exact interspace at which the epidural is performed is difficult to determine because of 
the severe obesity. A polyvinyl catheter is carefully inserted $5 \mathrm{~cm}$ into the epidural space after four to five ml of normal saline have been injected through the Tuohy needle to open the epidural space.

The patient is then placed in the supine position and 2 per cent lidocaine with $1: 200,000$ epinephrine is injected through the epidural catheter. The mean initial dose of local anaesthetic used in this series was 294 (SD \pm 54$)^{\circ} \mathrm{mg}$ (Table II). General anaesthesia is induced after the level of analgesia has been verified.

Anaesthesia is usually induced with intravenous thiopentone followed by intravenous succinylcholine to facilitate tracheal intubation. However, if a difficult tracheal intubation is expected due to a short, thick neck one must proceed with an awake intubation after topical anaesthesia has been applied to the upper airway.

Analgesia and muscle relaxation are maintained by the continued use of hourly epidural injections of 2 per cent lidocaine with epinephrine. ${ }^{30}$ Repeat doses of local anaesthetic are in the order of 50 per cent of the initial dose. Adequate tidal ventilation is obtained by ventilating the lungs with tidal volumes of 10 to $15 \mathrm{ml} / \mathrm{kg}$ at 10 to 12 times per minute with an Air-Shields volume ventilator. Tidal volume was measured during expiration with a Wright respirometer. The patient's tolerance to controlled ventilation, tracheal intubation and other manoeuvres beyond the level of the epidural block are guaranteed by using small intermittent intravenous doses of a short-acting narcotic (fentanyl citrate) and an inspired gas mixture of nitrous oxide and oxygen $(4: 2 \mathrm{~L})$.

Central venous pressure and arterial lines should be established for continuous monitoring, direct blood pressure recording and intermittent blood gas analysis.

Upon completion of the operation, the tracheal tube is removed and spontaneous respiration allowed with oxygen delivered by a high humidity mask. Epidural analgesia is maintained with an appropriate volume of local anaesthetic given at hourly intervals. The patient is nursed at $45^{\circ}$ in an attempt to maintain the tidal ventilation above closing volume. ${ }^{19.24}$ The duration of anaesthesia and the length of stay in the recovery room are shown in Table IV. With this regimen the patient remains comfortable during chest physiotherapy, deep-breathing exercises and can be turned frequently. Regular determinations of vital capacity, ${ }^{31}$ and blood gases with serial chest X-rays are used to evaluate the patient's progress. Most patients are able to ventilate adequately, cough and turn without the aid of epidural analgesia within 24 hours. Small doses of narcotics for analgesia may be required over the next 24 to 48 hours.

The mean stay in hospital after operation was 11 days (Table IV). This figure excludes two patients, one of whom died of a pulmonary embolus four days after operation and another who remained in hospital forty-two days due to complications arising from the operation. The post-operative complications were considered to be those noted clinically and those found by X-ray examination (Table V).

\section{Discussion}

Facilitation of post-operative care is the rationale for the use of epidural anaesthesia and post-operative analgesia. Post-operatively, pain, a large body mass, and ${ }^{\circ} \mathrm{SD}=$ Standard deviation. 
TABLE IV

\begin{tabular}{lccc}
\hline \hline & $\begin{array}{c}\text { Duration of } \\
\text { Anaesthesia } \\
\text { (Hours) }\end{array}$ & $\begin{array}{c}\text { Duration in } \\
\text { Recovery room } \\
\text { (Hours) }\end{array}$ & $\begin{array}{c}\text { *Hospitalization } \\
\text { Post Surgery } \\
\text { (Days) }\end{array}$ \\
\hline Mean & 4.2 & 26 & 11 \\
S.D. & \pm 1.0 & \pm 9 & \pm 2 \\
\hline
\end{tabular}

*Excludes two patients hospitalized for 4 and 42 days (see text).

S.D. = Standard deviation.

TABLE V

Post-Operative Pulmonary Complications

\begin{tabular}{lll}
\hline $\begin{array}{c}\text { Patient } \\
\text { Weight } \\
\text { (lb) }\end{array}$ & \multicolumn{1}{c}{ Clinical \& Laboratory } & \multicolumn{1}{c}{ Chest X-Ray } \\
\hline 380 & Low PaOz & $\begin{array}{c}\text { Interstitial pulmonary } \\
\text { oedema }\end{array}$ \\
340 & Cyanosis, dyspnoea, low Paos & Nil \\
395 & Febrile - due to intra- & $\begin{array}{l}\text { Pulmonary embolus } \\
8 \text { days post-operative }\end{array}$ \\
235 & abdominal complications & Nil \\
375 & Fever - chronic bronchitis & Atelectasis \\
\hline
\end{tabular}

the supine position guarantee a decrease in F.R.C. and a shift of tidal ventilation below closing volume. ${ }^{18.32}$ Intelligent therapy includes optimum analgesia, an increased inspired oxygen concentration and the use of all possible measures to ensure an F.R.C. above closing volume or at least similar to the pre-operative relationship. Epidural analgesia avoids post-operative mechanical ventilation and the attendant potent central depressants or muscle relaxants required to control respiration. In extubated patients narcotic analgesics are avoided. Patients who receive epidural rather than narcotic analgesia after upper abdominal operations have higher oxygen saturations on the day following the operation. ${ }^{31}$ Usually the pain from abdominal operations is associated with thoracic muscle spasm, increased intrathoracic pressure and decreased lung volumes, including the F.R.C. ${ }^{33}$ This may be associated with post-operative hypoxaemia. ${ }^{34}$ Adequate epidural analgesia without central depression may alter this sequence and partially restore the decreased F.R.C. towards normal. ${ }^{35}$ Furthermore, during epidural analgesia patients can easily be nursed in a seated position, which further allows the F.R.C. to return towards pre-operative levels. Significantly none of the 16 patients in this series required post-operative mechanical ventilation and none required therapy other than that outlined above.

\section{SUMMARY}

Sixteen extremely obese patients were anaesthetized for intestinal short circuiting operations. Severe obesity may cause pathological cardio-pulmonary changes. Cardiovascular alterations include increased systemic, pulmonary artery and pulmon- 
ary capillary venous pressure. Cardiac output, total blood volume and left ventricular work increase.

Expiratory reserve volume and consequently functional residual capacity decrease with gross obesity. Functional residual capacity falls below closing volume and inspired gas may be distributed to non-dependent lung zones, resulting in decreased ventilation/perfusion ratios and arterial hypoxaemia. Low total respiratory compliance increases the oxygen cost of the work of breathing.

Obesity may change the dose requirements for regional anaesthesia and longacting muscle relaxants. General anaesthesia may also reduce functional residual capacity.

We used a technique of anaesthesia which consisted of epidural analgesia with intra-operative mechanical ventilation and which specifically avoided volatile inhalation agents and long-acting muscle relaxants. All patients were extubated immediately after operation and returned to the recovery room for an average duration of 26 hours. Post-operative treatment included humidified oxygen, chest physiotherapy and elevation of the head of the bed to $45^{\circ}$. Each patient's respiratory progress was monitored by repeated determinations of arterial blood gases and vital capacity and by serial chest $\mathrm{X}$-rays. None of the patients in this group required post-operative tracheal intubation and mechanical ventilation.

\section{RÉSUMÉ}

L'étude porte sur 16 malades très obèses anesthésiés pour "by-pass" iléal. Une obésité importante peut entraîner des changements cardio-pulmonaires. On observe fréquemment de l'hypertension artérielle, de l'hypertension pulmonaire artérielle et veineuse. Le débit cardiaque, le volume sanguin total et le travail du ventricule gauche sont augmentés.

Le volume de réserve expiratoire et, par conséquent, la capacité résiduelle fonctionnelle sont diminués dans l'obésité grave. La FRC baisse sous le volume de fermeture et les gaz inspirés peuvent se distribuer aux parties non dépendantes du poumon, entraînant une hypoxémie secondaire à une diminution du rapport ventilation/perfusion. La compliance pulmonaire totale est basse ce qui augmente le travail respiratoire et la consommation d'oxygène.

L'obésité peut modifier les doses requises en anesthésie régionale et en relaxants musculaires à longue action. L'anesthésie générale contribue à diminuer la capacité résiduelle fonctionnelle.

Notre technique d'anesthésie comprend : analgésie par épidurale et ventilation mécanique per-opératoire. On évite les agents volatiles et les relaxants musculaires à longue action.

Tous les malades sont extubés immédiatement après chirurgie, et transférés à la salle de réveil où la durée du séjour moyen ne dépasse pas 26 heures. Le traitement post-opératoire comprend: oxygène humidifié, physiothérapie pulmonaire et tête du lit levée à $15^{\circ}$. On fait des contrôles de gaz artériels, de capacité vitale et des R-X pulmonaires.

Aucun des malades de ce groupe ne fut intubé, ni ventilé mecaniquement en post-opératoire. 


\section{REFERENCES}

1. Edelist, G. Extreme obesity. Anesthesiology 29: 846 (1968).

2. Vauchan, R.W. \& Roa, N.L. A case of morbid obesity. Anesthesiology 39: 107 (1973).

3. Catennaci, A.I., Anderson, J.D., \& Boersma, D. Anesthetic hazards of obesity. J.A.M.A. 175: 657 (1973).

4. Noble, A.B. The problem of obesity in anaesthesia for abdominal surgery. Canad. Anaes. Soc. J. 9: 6 (1962).

5. McIntYne, J.W.R. Problems for the anaesthetist in the care of the obese patient. Canad. Anaes. Soc. J. 15: 317 (1968).

6. Burwell, C.S., Robin, E.D., Whaley, R.D., \& Bickleman, A.G. Extreme obesity associated with alveolar hypoventilation. A Pickwickian Syndrome. Amer. J. Med. 21: 811 (1956).

7. Gould, A.B. Effect of obesity on respiratory complications following general anesthesia. Anesth. \& Analg. 41: 448 (1962).

8. Postrewait, R.W. \& Johnson, W.D. Complications following surgery for duodenal ulcer in obese patients. Arch. Surg. 105: 438 (1972).

9. Alexander, J.K. Chronic heart disease due to obesity. J. Chronic Dis. 18: 895 (1965).

10. Alexander, J.K. \& Peterson, K.L. Cardiovascular effects of weight reduction. Circulation. 45: 310 (1972).

11. Backman, L., Freyschuss, V., Hollbug, D., \& Melcher, A. Cardiovascular function in extreme obesity. Acta. Med. Scand. 193: 437 (1973).

12. Alexander, J.K., Dennis, E.W., Smith, W.G., Amad, K.M., Duncan, W.C., \& Austin, R.C. Blood volume, cardiac output and distribution of systemic blood flow in obesity. Cardiov. Res. Cent. Bull. Baylor University Coll. Med. 1: 39 (1963).

13. Amad, K.M., Brennan, J.C., \& Alexander, J.K. The cardiac pathology of chronic exogenous obesity. Circulation. 32: 740 ( 1965 ).

14. Alexander, J.K. Obesity and cardiac performance. Amer. J. Cardiol, 14: 860 (1964).

15. Prys-Roberts, C., Greene, L.T., Meloche, R., \& Fö̈x, P. Studies of anaestheria in relation to hypertension. II. Haemodynamic consequences of induction and endotracheal intubation. Brit. J. Anaesth. 43: 531 (1971).

16. Dingle, M.R. Antihypertensive drugs and anaesthesia. Anaesthesia 21:151 (1966).

17. Holly, H.S., Milic-Emill, J., Becklake, M.R., \& Bates, D.V. Regional distribution of pulmonary ventilation and perfusion in obesity. J. Clin. Invest. 46: 475 (1967).

18. Craig, D.B., Wahba, W.M., Don, H.F., Couture, J.G., \& Becklake, M.R. "Closing volume" and its relationship to gas exchange in seated and supine positions. J. Appl. Physiol. 31: 717 (1971).

19. Craig, D.B., Wahba, W.M., \& Don, H.F. Airway closure and lung volumes in surgical positions. Canad. Anaes. Soc. J. 18: 92 (1971).

20. Naimark, A. \& Cherniak, R.M. Compliance of the respiratory system and its components in health and obesity. J. Appl. Physiol, 15: 377 (1960).

21. Gilbert, R., Sipple, J.H., \& Auchincloss, J.H. Respiratory control and work of breathing in obese subjects. J. Appl. Physiol. 16: 21 (1961).

22. Don, H.F., Wahba, W.M., Caudrado, L., \& Kalkar, K. The effects of anesthesia and 100 per cent oxygen on the functional residual capacity of the lungs. Anesthesiology 32 : $521(1970)$.

23. Don, H.F., Wahba, W.M., \& Craig, D.B. Airway closure, gas trapping and functional residual capacity during anesthesia. Anesthesiology 36:533 (1972).

24. Couture, J., Picken, J., Trop, D., Riff, F., Lousada, N., Housley, E., \& Bates, D.V. Airway closure in normal, obese and anesthetized supine subjects. Abs. Fed. Proc. 29: 269 (1970).

25. Weenig, C.S., Pietak, S., Hickey, R.F., \& Fairley, H.B. Relationship of pre-operative closing volume to functional residual capacity and alveolar-arterial oxygen difference during anesthesia with controlled ventilation. Anesthesiology 41: 3 (1974).

26. Warner, W.A. \& Garretr, L.P. The obese patient and anesthesia. J.A.M.A. 205: 102 (1968).

27. Hackney, J.D., Crone, M.G., Collier, C.C., Roxaw, S., \& Greicgs, D.E. Syndrome of obesity and hypoventilation: studies of etiology. Ann. Int. Med. 51: 541 (1959).

28. KerR, M.G., SCOTt, D.B., \& SAMUEL, E. Studies of the inferior vena cava in late pregnancy. Brit. Med. J. 1: 532 (1964). 
29. KING, G.E. Errors in clinical measurement of blood pressure in obesity. Clin. Sc. $32 ; 223$ (1967).

30. Bromace, P.R. Physiology and pharmacology of epidural analgesia. Anesthesiology 28: 592 (1967).

31. Miller, L., Gertel, M., Fox, G.S., \& MacLean, L.D. A comparison of narcotic and epidural analgesia on post-operative respiratory function. Amer. J. Surg. In Press.

32. Alexander, J.I., Spence, A.A., Parikh, R.K., \& Stuart, B. The role of the airway closure in post-operative hypoxaemia. Brit. J. Anaesth. 45: 34 (1973).

33. Bromage, P.R. Extradural analgesia for pain relief. Brit. J. Anaesth. 39: 721 (1967).

34. Alexanden, J.I., Horton, P.W., Millar, W.T., \& Spence, A.A. Lung volume changes in relation to airway closure in the post-operative period: A possible mechanism of postoperative hypoxaemia. Brit. J. Anaesth. 43: 1196 (1971).

35. WAHBa, W.M., Don, H.F., \& Bhomage, P.R. Post-operative epidural analgesia: its effects on functional and vital capacities. Annals of the Royal College of Physicians and Surgeons of Canada 7: 60 (1974). 